\title{
Plataformas e Conexões em Implante: Uma Revisão de Literatura
}

\author{
Luciete Frota de Oliveira ${ }^{l}$; Fernando de Góes Ladeia ${ }^{2}$
}

\begin{abstract}
Resumo: A implantodontia osseointegrada na Odontologia possibilita inúmeras abordagens clínicas. Dentre os possíveis tipos de modelos de implantes podem-se enfatizar as plataformas e conexões usadas para sustentação. Em se tratando de conexões, estas devem manter-se estável, evitando o afrouxamento ou fratura dos parafusos ou pilares além de permitir uma distribuição de cargas compatível com a fisiologia dos tecidos de suporte. Nesse sentido, o objetivo deste estudo é apresentar e discutir os estudos encontrados na literatura a respeito do tema Conexões Plataformas em Implantes, demonstrando os benefícios comprovados destes materiais nos implantes dentários. Para isso foi realizada uma busca eletrônica de artigos científicos nas plataformas do Scielo, PubMed e MEDLINE como meios de busca e bases de dados, utilizando as palavras-chave "Plataformas em Implante" e "Conexões em Implante", selecionadas e com títulos de assuntos médicos apropriados.
\end{abstract}

Palavras-chave: Conexões; Implantes; Plataformas.

\section{Platforms and Connections in Implant: A Literature Review}

\begin{abstract}
The osseointegrated implantodontia in dentistry makes possible numerous clinical approaches. Among the possible types of implant models, it is possible to emphasize the platforms and connections used for support. In the case of connections, they must remain stable, avoiding the loosening or fracture of the screws or pillars, besides allowing a distribution of loads compatible with the physiology of the supporting tissues. In this sense, the objective of this study is to present and discuss the studies found in the literature regarding the topic Connections Platforms in Implants, demonstrating the proven benefits of these materials in dental implants. For this, an electronic search of scientific articles on the Scielo, PubMed and MEDLINE platforms was conducted as search media and databases, using the keywords "Platforms in Implant" and "Connections in Implant", selected and with titles of subjects appropriate doctors.
\end{abstract}

Keywords: Connections; Implants; Platforms.

\footnotetext{
${ }^{1}$ Graduanda em Odontologia pela Faculdade Independente do Nordeste. Contato: luciete-frota @ hotmail.com;

${ }^{2}$ Especialização em Cirurgia Buco Maxilo Facial pela Universidade José do Rosário Vellano, Brasil(2011). Professor da Faculdade Independente do Nordeste, Brasil.
} 


\section{Introdução}

A Implantodontia proporciona constantes avanços e modificações nos âmbitos científico e tecnológico da reabilitação oral, dentro desses estudos as conexões e plataformas vem sendo estudadas para serem mais eficientes e são primordiais ao sucesso do implante e da saúde dos tecidos circundantes. A adaptação destes componentes a estrutura dental é inerente ao desafio de desenvolver cada vez mais, melhores formas de conectar o pilar dos implantes ${ }^{1,2}$.

Em se tratando de conexões, conforme afirma Rezende et al 2015, estas devem manterse estáveis, evitando o afrouxamento ou fratura dos parafusos ou pilares além de permitir uma distribuição de cargas compatível com a fisiologia dos tecidos de suporte. Esta estabilidade pode ser analisada tanto no plano vertical quanto horizontal, interferindo na mesma a liberdade rotacional da conexão ${ }^{3}$.

No intuito de minimizar as limitações das próteses sobre implantes, ao longo do tempo, as conexões foram sendo desenvolvidas para serem mais eficientes e hoje são encontradas uma infinidade de opções no mercado, como a octogonal, hexagonal, parafuso de cone, cilindro hexadecimal, spline, tri-canal para tubo de cames dentre outras. Além disso, estudos demonstram que o sucesso do implante não depende somente da osseointegração, mas de outros fatores como a oclusão correta do paciente, e os componentes protéticos que são elementos fundamentais para o sucesso e manutenção ${ }^{4-6}$.

Além destes fatores, para que se tenha um sucesso na prótese sobre implante, deve-se considerar não só o desempenho mecânico, mas também os aspectos biológicos e estéticos, nesse sentido é que surgiram as conexões internas, bem como o conceito de plataforma switch. O conceito de plataforma switch introduzida por LAZZARA PORTER na implantodontia moderna vem apresentando resultados satisfatórios do ponto de vista de proporcionar estabilidade os tecidos periimplantares. ${ }^{3}$

A junção pilar implante e a interface protética podem ser classificadas como interna ou externa, a externa mais comum é a hexagonal, tendo a octogonal e a spline com projeções interdigitadas. As internas incluem o Morse Taper, o hexágono interno e octógono interno e esta pode ser feita por encaixe, ou ajustada com atrito ${ }^{7-9}$. 
Muitas pesquisas destacam que a escolha da plataforma é crucial para manter a preservação da crista óssea, dando dessa forma uma maior estabilidade ao implante, buscando harmonia com os tecidos moles circundantes e gerando um aspecto estético satisfatório ${ }^{10}$.

Diante dos fatos supracitados, este estudo tem como objetivo apresentar e discutir os estudos encontrados na literatura sobre as Conexões e Plataformas em Implantes, destacando a relação dessas estruturas com o sucesso do implante e discorrer de maneira sucinta sobre os tipos mais utilizados na Odontologia.

\section{Material e Métodos}

Para a realização desse estudo foi realizada uma busca eletrônica de artigos científicos nas plataformas do Scielo, PubMed e MEDLINE como meios de busca e bases de dados, utilizando as palavras-chave "Plataformas em Implante" e "Conexões em Implante", selecionadas e com títulos de assuntos médicos apropriados. Somente artigos relevantes para a temática em questão, publicado em Inglês e/ou português em revistas cientificas datados entre 2012 e 2018 foram considerados para este estudo.

Os critérios de inclusão utilizados foram: artigos primários e de revisão e prospectivos publicados no idioma português e inglês realizados com este tema ou relacionado a este e livros relacionados à área de Implante. Como critérios de exclusão serão considerados estudos com mais de 5 anos de publicação

\section{Revisão de Literatura}

No protocolo original de Branemark a interconexão implante-pilar era constituída de um hexágono externo, que servia de conexão de transferência de torque durante a instalação do implante no osso e sequente conexão da extensão transmucosa, foi então o hexágono externo o primeiro tipo de plataforma a ser projetada e utilizada ${ }^{12}$.

Os sistemas de implantes que apresentam a conexão hexagonal externo, tem como função transmitir o torque durante a inserção, através do montador e, também, a de posicionar 
a prótese durante a reabilitação protética, evitando assim desvios rotacionais da peça, entretanto apesar de serem os mais comercializados devido sua simplicidade na instalação e apresentarem uma gama de componentes protéticos, fato este que favorece a diversas escolhas para a solução de cada caso, apresentam o percalço da altura ser limitada a $1 \mathrm{~mm}$ a fim de garantir, assim, a estética final da prótese implanto-suportada ${ }^{13,14}$.

Quanto às complicações apresentadas pela escolha deste tipo de plataforma é destacada a possibilidade da mesma sofrer deformação durante o processo de inserção do implante na loja óssea, requerer uma precisão dimensional mais exata, quanto possível, para garantir o encaixe do componente protético sem que haja folgas excessivas, apresentar maior probabilidade de concentração de forças na região coronária, além do fato da desadaptação implante-prótese facilitar a adesão de biofilme na plataforma e consequentemente induzir a saucerização ${ }^{14,15}$.

De acordo com alguns autores ${ }^{12-15}$, dentre as conexões já existentes, as de plataforma interna seriam uma evolução do hexágono externo, apresentando as vantagens de favorecer menor afrouxamento e fraturas do implante, bem como absorver de melhor forma as cargas externas, dissipando-as no sentindo axial do corpo do parafuso diminuindo dessa forma as tensões sobre a crista óssea ${ }^{16}$.

Os implantes de conexão hexagonal interna apresentam como grande prerrogativa, sua resistência mecânica, devido fato de ter uma maior área de contato entre o implante e o componente protético, quando comparado com os implantes de hexágono externo. Apresentam a grande vantagem de não possuir montador para inserção do implante, na qual a instalação do mesmo é feita por meio de uma chave de torque, que tem a função de transportar o implante do sítio cirúrgico até a região alveolar, diminuindo desta forma o tempo cirúrgico e minimizando assim o risco de contaminação durante a cirurgia ${ }^{15,17}$

O cone morse é um sistema de implante que possui conexão interna precisa com o componente protético, na qual o pilar possui uma forma mais estreita na sua base, e esta é instalada com conexão morse no interior do implante, de forma muito justa. Este tipo de conexão surgiu com o intuito de direcionar melhor as cargas recebidas para a região mais apical do implante, contrário do que ocorre no tipo de conexão externa ${ }^{18}$.

Em todos os sistemas onde é utilizado um parafuso para unir o intermediário ao implante pode-se observar a presença de uma lacuna (gap) entre as duas peças, e as consequências oriundas da formação dessa fenda pode ser mecânica ${ }^{15}$, onde os problemas estão relacionados 
com micromovimentos do intermediário e possíveis fraturas da porção intraóssea do implante. Ou biológica onde os fatores estão relacionados com a invasão de bactérias nesse espaço e posterior colonização destas na parte interna do implante ${ }^{16}$. Enquanto o tamanho de uma bactéria é de aproximadamente $0,5 \mu \mathrm{m} \mathrm{O}$ tamanho desse gap varia entre 40 e $100 \mu \mathrm{m}$, facilitando assim a propagação de bactérias ${ }^{17}$.

A doença peri-implantite têm sido associada à presença desse espaço entre o intermediário e o implante, onde hipóteses circundam a ideia que a colonização bacteriana ocorre na fase cirúrgica e através do gap, formando um nicho bacteriano no interior do implante $^{19}$.

Estudos realizados em implante com plataforma hexagonal externa levou à classificação, da perda óssea nas áreas próximas ao implante, de aceitável quando a mesma ocorre em até $1 \mathrm{~mm}$ no primeiro ano de função e perca de $0,1 \mathrm{~mm}$ por ano a partir de então, entretanto têm-se discutido que essa perda pode ser uma possível predecessora da doença periimplantar ${ }^{17}$.

Em um seccionamento transversal, observa-se que os pilares, apresentados nos implantes do tipo cone morse, são menores do que a largura da plataforma do implante devido à sua conexão cônica, possibilitando dessa forma a obtenção da denominada plataforma switching e diminuindo consequentemente a existência de gaps $^{19}$.

Rocha et $\mathrm{al}^{20}$. (2015) afirmam que o uso da plataforma switching é promissor na Implantodontia, uma vez que a sua utilização promoverá a migração das células inflamatórias para mais próximo da porção central do eixo do implante e consequentemente distante da crista alveolar limitando dessa forma a reabsorção do óssea.

A colocação de um pilar de menor diâmetro no implante além de limitar acaba reduzindo a reabsorção da crista óssea, auxiliando de forma significativa na preservação dos tecidos moles e duros circundantes do implante beneficiando, assim, a estabilidade primária e estética ${ }^{10,16,19-}$ 24. 


\section{Discussão}

A falha que ocorre com maior frequência em reabilitações com próteses unitárias implanto suportadas é a fratura ou afrouxamento do parafuso, gerando assim uma perda da précarga $^{7,15}$ onde essa pré-carga está associada a diversos fatores, dentre esses o sistema de conexão está relacionado, uma vez que participa dos micro-movimentos entre implante e abutment ${ }^{4,8}$.

A busca por plataformas implante-abutment cada vez mais estáveis e com resistência às forças mastigatórias levou ao desenvolvimento de diversas conexões, internas e externas, que estão disponíveis atualmente no mercado.

Shibata e colaboradores ${ }^{6}$ (2015), em busca de maior compreensão acerca da mecânica dos sistemas de conexão do tipo hexagonal externa e cone morse, realizaram uma análise de elementos finitos, onde a plataforma cônica passou por um efeito cunha, enquanto o estresse era concentrado nas duas primeiras roscas do parafuso do abutment, e constatou-se que os níveis de fadiga foram consideravelmente superiores no tipo hexágono externo, fato este que corrobora com os demais estudos apresentados uma vez que $\operatorname{Santos}^{5}$ (2013) relatou a maior capacidade do cone morse de distribuir as forças de forma axial no corpo do implante evitando dessa forma o estresse na peça protética.

Ainda avaliando a resistência à fadiga, Vandeweghe et al $^{16}$ (2015) realizou uma comparação entre dois sistemas, respectivamente: 1)Hexágono externo e 2) Cone morse, ambos receberam cargas cíclicas em sentido perpendicular ao seu longo eixo, visando simular uma função de 6 anos, visou-se uma valor máximo de 1.800 .000 ciclos. Foi observada a fratura do parafuso de conexão de todas as amostras do tipo hexagonal externa, enquanto no cone morse não houve nenhuma.

Oliscovicz e colaboradores ${ }^{2}$ (2013) compararam o nível de infiltração de bactérias na superfície implante-conexão, em 5 sistemas de implantes com plataformas hexágono externa e cone morse, onde observou-se que essa penetração ocorria em todos os tipos de sistemas e que esta diminuía a medida que o torque do parafuso aumentava, entretanto como citado por Calabrez-Filho e colaboradores ${ }^{1}$ (2012) e Palmeira et al. ${ }^{14}$ (2018), essa infiltração bacteriana é menor no sistema cone morse devido a plataforma switching apresentada por esse tipo de conexão.

\footnotetext{
1115 Id on Line Rev. Mult. Psic. V.12, N. 42, p. 1110-1118, 2018 - ISSN 1981-1179
} Edição eletrônica em http://idonline.emnuvens.com.br/id 
Em relação à perda óssea marginal na região cervical do implante, o tipo cone morse apresenta menores perdas que o esperado ( $1 \mathrm{~mm}$ em média no primeiro ano), do sistema hexagonal externo ${ }^{5}$. De acordo com Rezende et al $^{3}$ (2014) essa diminuição da perda óssea está relacionada à teoria da plataforma switching onde colonização bacteriana da interface estaria a uma distância biológica satisfatória; e o fato do cone morse distribuir melhor as cargas axiais ${ }^{22-}$ 24.

Quanto às falhas, como a fratura e afrouxamento do parafuso, de acordo com Rocha et $\mathrm{al}^{20}(2015)$ e Nogueira et $\mathrm{al}^{21}$ (2012), descreveram que atuam como medida de sobreaviso que algo na carga do implante está incorreto, considerando essas como benéficas desde que não tornem o sistema impossibilitado de reversão.

Em relação às avaliações mecânicas abordadas no presente trabalho, de forma geral, observa-se uma melhor performance das plataformas internas frente às externas, entretanto, essa análise deve ser feita de maneira independente uma vez que envolvendo a anatomia humana nada pode ser tomado como verdade absoluta, devido fato de variar de acordo com

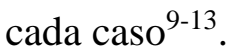

\section{Conclusões}

Após estudos de artigos podem concluir que o desenvolvimento de novos tipos de conexões para implantes foi realizado a fim de obter melhor sucesso na união entre prótese e implantes; em um ponto de vista geral é observado um melhor desempenho das plataformas do tipo interna quando comparadas às externas, destacando principalmente o tipo cone morse.

O sistema implante-abutment deve ter um índice menor de tolerância que o biológico, tendo em vista que o ponto mais frágil seja localizado no parafuso do implante, evitando assim possíveis fraturas no completo osso-implante.

1116 Id on Line Rev. Mult. Psic. V.12, N. 42, p. 1110-1118, 2018 - ISSN 1981-1179 Edição eletrônica em http://idonline.emnuvens.com.br/id 


\section{Referências}

1.Calabrez-Filho S, Cunha N, Calabrez V, Calabrez A. Plataforma reduzida, uma solução estética. Revisão de Literatura. Rev. Bras. Odontol. 2012; 69(2): 207-211.

2.Oliscovicz NF, Valente MC, Marcantonio JE, Shimano AC, Reis AC. Estudo in vitro da influência do formato e do tratamento de superfície de implantes odontológicos no torque de inserção, resistência ao arrancamento e frequência de ressonância. Rev. odontol. UNESP. 2013; 42(4): 283 290.

3.Rezende CEE, Albarracín ML, Rubo JH, Pegoraro LF. Conexões implante/pilar em implantodontia. Innov Implant J. 2014; 9 (2-3): 58-64.

4.Varise C, Abi RF, Messias AM, Neves FD, Segalla JC, Reis JM. Sistema Cone Morse e utilização de pilares com plataforma switching. Rev. Bras. Odontol. 2015; 72(1-2): 56-61.

5.Santos AMT. Boimechanical study of prosthetic interfaces. A literature review. Dental Press Implantol.2013; 7(4):90-7.

6. Shibata Y, Tanimoto Y, Maruyama N, Nagakura M. A review of improved fixation methods for dental implants. Part II: biomechanical integrity at bone-implant interface. J Prosthodont Res. 2015; 59(2):84-95.

7.Chrcanovic BR, Albrektsson T, Wennerberg A. Platform switch and dental implants: A metaanalysis. J Dent. 2015; Jun;43(6):629-46.

8.Yang TC1, Maeda Y. The biomechanical effect of platform switching on external- and internalconnection implants. Int J Oral Maxillofac Implants. 2013; Jan-Feb;28(1):143-7.

9.Pita M, Anchieta R, Barão VA, Garcia R, Pedrazzi V Assunção W. Prosthetic Platforms in Implant Dentistry. The Jou Cran Surg, 2013; 22(6):2327-31.

10.Valim AM. Influência dos tipos de conexão implante-pilar protéico na perda óssea marginal periimplantar: revisão sistemática da literatura, 2013, (Monografia), Universidade Federal do Rio Grande do Sul. Faculdade de Odontologia. Curso de Odontologia.51f

11.Cerqueira Filho JR. Análise da taxa de sobrevivência de implantes dentários com diferentes tipos de conexões. Dissertação (mestrado). Universidade Sagrado Coração, Bauru, 2017, $90 \mathrm{f}$.

12.Borie E, Orsi IA, Noritomi PY, Kemmoku DT. Three-Dimensional Finite Element Analysis of the Biomechanical Behaviors of Implants with Different Connections, Lengths, and Diameters Placed in the Maxillary Anterior Region. Int J Oral Maxillofac Implants. 2016; 31(1):101-10.

13.Song GA. Three Dimensional finite element stress analysis of Post Core Reinforced Endodontically treated Teeth. Thesis Practicum submitted to the Faculty of Graduates Studies of The University of Manitoba, 2015.

14. Palmeira JA, Silva LMN, Araújo TN, Santos TA, Rocha JF, Ribeiro ED. Implante com estética imediata em região anterior de maxila: relato de caso. Arch Health Invest. 2018; 7(1): 40-51.

\section{Id on Line Rev. Mult. Psic. V.12, N. 42, p. 1110-1118, 2018 - ISSN 1981-1179} Edição eletrônica em http://idonline.emnuvens.com.br/id 
15. Cassetta M, et al. Accuracy of Implant Placement with a Stereolithographic Surgical Template. The Internat Jour Of Oral \& Maxillofac Implan. 2012; 27(3):655-63.

16. Vandeweghe S, De Bruyn H. A within-implant comparison to evaluate the concept of platform switching. A randomised controlled trial. Europ Jour of Oral Implanto. 2012; 5(3): 253-62.

17. Heijdenrijk K, Raghoebar GM, Meijer HJ, Stegenga B, van der Reijden WA. Feasibility and influence of the microgap of two implants placed in a non-submerged procedure: a five-year follow-up clinical trial. J Periodontol. 2016;77(6):1051-60.

18. Scarano A, Assenza B, Piattelli M, Iezzi G, Leghissa GC, Quaranta A, et al. A 16-year study of the microgap between 272 human titanium implants and their abutments. J Oral Implantol. 2015;31(6):269-75

19. Varise CG, et al. Morse Taper System and platform switching abutment application. Rev. brasile. odontol. 2015; 72(1/2): 56-60

20. Rocha CS, et al. Plataforma switching: considerações atuais. Rev de Odontol da Univers de São Paulo. 2015; 27(1): 43-8.

21. Nogueira MCF, Bacchi A, Santos MBF, Mesquita MF, Consani RLX. Efeitos da plataforma switching em reabilitações implantossuportadas: revisão de literatura. RFO, Passo Fundo 2012; 17(1):113-9

22. Alonso-González R, Aloy-Prósper A, Peñarrocha-Oltra D, Peñarrocha- -Diago MA, PeñarrochaDiago M. Marginal bone loss in relation to platform switching implant insertion depth: An update. J Clin Exp Dent 2012 4(3):173-9

23. Salimi H, Savabi O, Nejatidanesh F. Current results and trends in platform switching. Dent Res J. 2011; 8(Suppl 1):30-6.

24. Linkevicius T, Apse P, Grybauskas S, Puisys A. Influence of thin mucosal tissues on crestal bone stability around implants with platform switching: a 1-year pilot study. J Oral Maxillofac Surg 2010 Sep;68(9):2272-7

\section{Como citar este artigo (Formato ABNT):}

OLIVEIRA, Luciete Frota de; LADEIA, Fernando de Góes. Plataformas e conexões em implante: Uma Revisão de literatura. Id on Line Rev.Mult. Psic., 2018, vol.12, n.42, p. 1110-1118. ISSN: 19811179.

Recebido: 25/06/2018;

Aceito: 29/10/2018 